\title{
Aggressive nutrition in extremely low birth weight infants: Impact on Parenteral Nutrition Associated Cholestasis and growth
}

\author{
Andreas Repa ${ }^{\text {Corresp., }}{ }^{1}$, Ruth Lochmann ${ }^{1}$ ， Lukas Unterasinger ${ }^{1}{ }^{\text {, }}$ Michael Weber ${ }^{2}$, Angelika Berger ${ }^{1}$, Nadja \\ Haiden ${ }^{1}$ \\ 1 Department of Pediatrics and Adolescent Medicine, Division of Neonatology, Pediatric Intensive Care and Neuropediatrics, Medical University of Vienna, \\ Vienna, Austria \\ 2 Department of Radiology, Medical University of Vienna, Vienna, Austria \\ Corresponding Author: Andreas Repa \\ Email address: andreas.repa@meduniwien.ac.at
}

Background. Parenteral nutrition associated cholestasis (PNAC) is a frequently observed pathology in extremely low birth weight (ELBW) infants. Its pathogenesis is determined by the composition and duration of parenteral nutrition (PN) as well as the tolerance of enteral feeds (EF). "Aggressive" nutrition is increasingly used in ELBW infants to improve postnatal growth. Little is known about the effect of "aggressive" nutrition on the incidence of PNAC. We analyzed the influence of implementing an "aggressive" nutritional regimen on the incidence of PNAC and growth in a cohort of ELBW infants.

Methods. ELBW infants were nourished using a "conservative" (2005-6; $n=77$ ) or "aggressive" (2007-9; $\mathrm{n}=85$ ) nutritional regimen that differed in the composition of PN after birth as well as the composition and timing of advancement of EFs. We analyzed the incidence of PNAC (conjugated bilirubin $>1.5 \mathrm{mg} / \mathrm{dl}$ $(25 \mu \mathrm{mol} / \mathrm{l})$ ) corrected for confounders of cholestasis (i.e. NEC and/or gastrointestinal surgery, sepsis, birth weight, Z-score of birth weight, time on PN and male sex), growth until discharge (as the most important secondary outcome) and neonatal morbidities.

Results. The incidence of PNAC was significantly lower during the period of "aggressive" vs. "conservative "nutrition ( $27 \%$ vs. 46\%, P < 0.05; adjusted OR 0.275 [0.116 - 0.651], P < 0.01). Body weight $(+411 \mathrm{~g})$, head circumference $(+1 \mathrm{~cm})$ and length $(+1 \mathrm{~cm})$ at discharge were significantly higher. Extra-uterine growth failure (defined as a Z-score difference from birth to discharge lower than -1) was significantly reduced for body weight ( $85 \%$ vs. $35 \%$ ), head circumference (77\% vs. $45 \%$ ) and length (85\% vs. 65\%) ( $<<0.05$ ). The body mass index (BMI) at discharge was significantly higher (12.4 vs. 11.1 ) using "aggressive" nutrition and growth became more proportionate with significantly less infants being discharged below the $10^{\text {th }}$ BMI percentile (44\% vs. 9\%), while the percentage of infants discharged over the $90^{\text {th }} \mathrm{BMI}$ percentile ( $3 \%$ vs. $5 \%$ ) did not significantly increase.

Discussion. "Aggressive" nutrition of ELBW infants was associated with a significant decrease of PNAC and marked improvement of postnatal growth. 
1 AGGRESSIVE NUTRITION IN EXTREMELY LOW BIRTH WEIGHT INFANTS:

2 IMPACT ON PARENTERAL NUTRITION ASSOCIATED CHOLESTASIS AND

3 GROWTH

4 Andreas Repa ${ }^{1,}$, Ruth Lochmann ${ }^{1}$, Lukas Unterasinger ${ }^{1}$, Michael Weber ${ }^{2}$, Angelika Berger

$5{ }^{1}$ and Nadja Haiden ${ }^{1}$

6

$7{ }^{1}$ Department of Pediatrics and Adolescent Medicine, Division of Neonatology, Pediatric

8 Intensive Care and Neuropediatrics, Medical University of Vienna, Austria

$9 \quad{ }^{2}$ Department of Radiology, Medical University of Vienna, Austria

$11 *$ Corresponding author:

12 Andreas Repa, MD

13 Department of Pediatrics and Adolescent Medicine

14 Medical University of Vienna

15 Waehringer Guertel 18-20;

161090 Vienna, Austria (EU)

17 +43-140400-32320, Fax: +43-140400-39228

18 andreas.repa@meduniwien.ac.at 
ABSTRACT

Background. Parenteral nutrition associated cholestasis (PNAC) is a frequently observed pathology in extremely low birth weight (ELBW) infants. Its pathogenesis is determined by the composition and duration of parenteral nutrition (PN) as well as the tolerance of enteral feeds (EF). "Aggressive" nutrition is increasingly used in ELBW infants to improve postnatal growth. Little is known about the effect of "aggressive" nutrition on the incidence of PNAC. We analyzed the influence of implementing an "aggressive" nutritional regimen on the incidence of PNAC and growth in a cohort of ELBW infants.

Methods. ELBW infants were nourished using a "conservative" (2005-6; n=77) or "aggressive" (2007-9; n=85) nutritional regimen that differed in the composition of PN after birth as well as the composition and timing of advancement of EFs. We analyzed the incidence of PNAC (conjugated bilirubin $>1.5 \mathrm{mg} / \mathrm{dl}(25 \mu \mathrm{mol} / \mathrm{l}))$ corrected for confounders of cholestasis (i.e. NEC and/or gastrointestinal surgery, sepsis, birth weight, Zscore of birth weight, time on PN and male sex), growth until discharge (as the most important secondary outcome) and neonatal morbidities.

Results. The incidence of PNAC was significantly lower during the period of "aggressive" vs. "conservative "nutrition (27\% vs. 46\%, P < 0.05; adjusted OR 0.275 [0.116 - 0.651], P < 0.01). Body weight $(+411 \mathrm{~g})$, head circumference $(+1 \mathrm{~cm})$ and length $(+1 \mathrm{~cm})$ at discharge were significantly higher. Extra-uterine growth failure (defined as a Z-score difference from birth to discharge lower than -1) was significantly reduced for body weight (85\% vs. $35 \%)$, head circumference (77\% vs. $45 \%)$ and length ( $85 \%$ vs. $65 \%)(\mathrm{P}<0.05)$. The body mass index (BMI) at discharge was significantly higher (12.4 vs. 11.1) using "aggressive" 
42 nutrition and growth became more proportionate with significantly less infants being

43 discharged below the $10^{\text {th }}$ BMI percentile ( $44 \%$ vs. $9 \%$ ), while the percentage of infants

44 discharged over the $90^{\text {th }}$ BMI percentile (3\% vs. $5 \%$ ) did not significantly increase.

45 Discussion. "Aggressive" nutrition of ELBW infants was associated with a significant 46 decrease of PNAC and marked improvement of postnatal growth. 


\section{INTRODUCTION}

48 Parenteral nutrition associated cholestasis (PNAC) is the most common form of liver 49 damage in neonates while receiving parenteral nutrition (PN) (Kelly 1998). Its prevalence was reported between $10 \%$ and $60 \%$ in neonatal intensive care units (Klein et al. 2010).

51 Preterm infants born < 1000 gram (extremely low birth weight (ELBW) infants) are at 52 particular risk to develop PNAC due to a prolonged dependence on PN, low tolerance of 53 enteral feedings (EF), immaturity of hepato-biliary function and infections (Beale et al. 54 1979; Beath et al. 1996; Drongowski \& Coran 1989). With regard to PN, high cumulative 55 doses of amino acids (Steinbach et al. 2008) and soybean based lipid emulsions (Carter et al. 2007; Clayton et al. 1993; Kurvinen et al. 2012) were suggested to play an important

57 role in PNAC pathogenesis. To avoid PNAC and other complications associated with PN, parenteral proteins and lipids were hence frequently withheld right after birth unless "metabolic tolerance" was assumed (Pereira 1995) and EFs were only cautiously introduced in fear of necrotizing enterocolitis (NEC)(Morgan et al. 2011). However, this "conservative" approach of nutrition caused a deficit in protein and energy supply (Embleton et al. 2001) leading to postnatal growth failure - a common phenomenon in ELBW infants (Fanaroff et al. 2007). Today, the contemporary nutritional practice has become more "aggressive" (Hay 2013) in terms of early application of higher amounts of amino acids and lipids in PN right after birth and more rapid progression of EFs with higher caloric density. To reduce growth failure of ELBW infants at our unit, we thus changed our nutritional approach from a "conservative" to a more "aggressive" regimen (Table 1). However, higher amounts of amino acids (Steinbach et al. 2008) and lipids

(Carter et al. 2007; Clayton et al. 1993; Kurvinen et al. 2012) in early PN may increase 
70 PNAC incidence. On the other hand, earlier intensive enteral nutrition may improve bile

71 flow and prevent PNAC. While regimens of "aggressive" nutrition including both aspects

72 are used in clinical routine more often, their influence on the incidence of PNAC has not

73 been investigated (Guellec et al. 2015). We therefore performed a retrospective

74 observational study with the primary aim to investigate the effect of implementing

75 "aggressive" nutrition on the incidence of PNAC and - as a secondary aim - to evaluate the

76 effects on growth in ELBW infants. 
78

79

80

81

82

83

84

85

86

87

\section{MATERIALS \& METHODS}

\section{Nutritional and clinical management of ELBW infants}

The nutritional guidelines for ELBW infants at our unit are shown in Table 1.

With "conservative" nutrition, PN was started after birth with glucose only, while protein and fat were slowly introduced during the first week of life. Enteral feedings were started using an extensively hydrolyzed formula (eHF) at half strength $(10 \mathrm{kcal} / \mathrm{oz})$ when the infant was clinically stable. As soon as half EF were tolerated, eHF was advanced to full strength (20 kcal/oz) and switched to preterm formula (24 kcal/oz) as soon as infants reached $1 \mathrm{~kg}$ of body weight. Advancements of EF were not defined using the “conservative” approach.

With "aggressive" nutrition, full PN was started with protein and fat on the first day of life. Enteral feeds were started using preterm formula (24 kcal/oz) on the first day of life. Clinicians were allowed to perform advancements of EF by a maximum of $20 \mathrm{ml} / \mathrm{kg} / \mathrm{d}$ which was considered to be safe in terms of triggering NEC (Tsang et al. 2005).

In both periods, mothers were encouraged to express breast milk, which was used instead of formula as soon as available. Fortification of mother's milk was performed using a bovine multicomponent fortifier that was added as soon as $140 \mathrm{ml} / \mathrm{kg} / \mathrm{d}$ ("conservative") or $100 \mathrm{ml} / \mathrm{kg} / \mathrm{d}$ ("aggressive") of EF were reached. In both periods the attending physicians individually prescribed EFs and PN. Physicians were trained to follow the new feeding guidelines by members of our nutrition team. 
98 The components used for preparation of PN did not change within the study period. In

99 particular the content of taurine in the amino acid solution $(0.3 \mathrm{~g} / 100 \mathrm{ml}$; Aminopaed 10\%;

100 Fresenius Kabi, Graz, Austria, EU) and the nature of lipid emulsion (exclusively soybean oil

101 based; Intralipid 20\%, Fresenius Kabi, Graz, Austria, EU) did not change. In both periods,

102 urodeoxycholic acid was used for treatment - but not prevention (Gokmen et al. 2012) - of

103 PNAC. Infants did not receive erythromycin (Aly et al. 2007; Gokmen et al. 2012; Ng et al.

104 2007) to reduce time until full enteral feeds. Fluconazole was used for fungal prophylaxis

105 from $04 / 2006$ (3mg/kg twice a week) for a maximum of six weeks if a central line was

106 present. All infants routinely received a peripherally inserted central catheter line for

107 application of PN, either on the second day of life or on the seventh day of life if an

108 umbilical venous line had been placed right after birth.

110 Study Design and Eligibility

111 The study was retrospective and observational. The primary aim was to evaluate the

112 impact of an "aggressive" versus a "conservative" nutritional regimen on the incidence of

113 PNAC in ELBW infants. The secondary aim was to compare postnatal growth. ELBW infants

114 born within a two-year period of "conservative" (01/2005 - 12/ 2006) or "aggressive"

115 (07/2007-06/2009) nutrition were screened for eligibility. Patients were excluded due to:

116 (i) cholestasis at birth, (ii) diseases associated with cholestasis (i.e. inborn errors of

117 metabolism, viral hepatitis, cystic fibrosis and any primary cholestatic liver diseases) that

118 were diagnosed while hospitalized and (iii) early death or transfer to another hospital (i.e.

119 within 28 days of life). Patients who died (but not those who were transferred) after 28 
120

121

122

123

124

125

126

127

128

129

130

131

132

133

134

135

136

137

138

139

140

141

days of life were excluded from growth analysis, due to the risk of distortion of weight measurements by perimortal edema.

\section{Data collection}

Data were retrieved from the electronic patient's charts (carevue®, Phillips Medical Systems, Eindhoven, The Netherlands, EU), the hospital's PN prescription software (VIEPNN (Horn et al. 2002), Medical University Vienna, Austria, EU) and discharge letters.

\section{Demographic and basic clinical parameters}

The full list of parameters is shown in Table 2. Prenatal steroids were defined as a full course (two doses) of betamethasone. Surfactant (200 mg/kg Curosurf®; Chiesi, Parma, Italia) was used in preterm infants with more than $35 \%$ oxygen on continuous positive airway pressure in the first 2 hours after birth. Starting from 2009, ELBW infants $<27+6$ weeks gestational age (GA) received surfactant prophylactically while spontaneously breathing as previously described (Klebermass-Schrehof et al. 2013). Percentiles and Zscores of weight, head circumference and length were determined according to Fenton et al. (Fenton \& Kim 2013) using a spreadsheet based calculator (Fenton 2013). Small for gestational age (SGA) was defined as birth weight $<10^{\text {th }}$ percentile. Infants of both study periods received neither probiotics nor lactoferrin for NEC/sepsis prophylaxis.

\section{Nutritional analysis in the first week of life}

Data on prescribed PN (fluids, glucose, protein and lipids per kg/d), EF (fluids and total 
142 calories per $\mathrm{kg} / \mathrm{d}$ ) and total energy and fluids in infants of the "conservative" and

143 "aggressive" period were expressed as the median during the first week of life (Table 3).

144 Total days on PN were defined as days on any PN - with or without lipids. Furthermore

145 infants with or without PNAC were compared for their parenteral and enteral nutritional

146 intake within each population - together with important parameters on demography,

147 morbidity and growth (Table 7).

148

149

\section{Neonatal outcome: PNAC and other neonatal morbidities}

150 Neonatal morbidities including the primary outcome are presented in Table 4. Laboratory

151 analyses including bilirubin with fractions were performed at least weekly as long as PN

152 was required, afterwards every 7-14 days and at discharge. Conjugated bilirubin was

153 measured by spectrophotometric quantitation (Vitros Chemistry System, Ortho Clinical

154 Diagnostics, Raritan, NJ, USA). Parenteral nutrition associated cholestasis was defined as

155 conjugated bilirubin $>1.5 \mathrm{mg} / \mathrm{dl}(25 \mu \mathrm{mol} / \mathrm{l})$ measured at two consecutive occasions

156 (Bines 2004) which corresponds closely to $>2 \mathrm{mg} / \mathrm{dl}$ direct bilirubin (Ye et al. 2015) .

157 Conjugated bilirubin levels were used as they are more accurate compared to direct

158 bilirubin (Doumas \& Wu 1991), in particular when bilirubin levels rise and persist over a

159 longer period of time (Ye et al. 2015). NEC was diagnosed either clinically (modified Bell's

160 stage $\geq$ IIa (Walsh \& Kliegman 1986)) or after surgical exploration. Focal intestinal

161 perforation was diagnosed after surgical exploration if a single perforation occurred in an

162 otherwise healthy bowel. Intraventricular hemorrhage (IVH) grade 3/4 and cystic

163 periventricular leucomalacia were diagnosed by ultrasound (de Vries et al. 1992; Volpe

164 1989) that was performed every 7-14 days. Bronchopulmonary dysplasia (BPD) was 
165 defined as need for supplementary oxygen after 36+0 weeks of GA. Pharmacological

166 treatment of persistent ductus arteriosus (PDA) using ibuprofen was performed based on

167 its hemodynamic significance in ultrasound and cardiorespiratory stability. Screening for

168 retinopathy of prematurity (ROP) by indirect ophthalmoscopy was started at 5 weeks of

169 chronological age.

170 A multivariate analysis on the effect of "aggressive" nutrition on the incidence of PNAC

171 corrected for confounders (see statistics) is presented in Table 5.

\section{Neonatal outcome: Growth}

173 Body measures (body weight, crown-heel length and head circumference) are presented

174 together with Z-scores in standard deviations (SD) and the body mass index (BMI, weight

175 in $\mathrm{g}^{*} 10 / \mathrm{cm}^{2}$ ) with respective percentiles, the percentage of infants $<10^{\text {th }}$ and $>90^{\text {th }} \mathrm{BMI}$

176 percentile as well as Z-scores at birth (Table 2) and at discharge (Table 6). The BMI

177 percentiles and Z-scores were generated by the authors of the publication by Olsen et al

178 (Olsen et al. 2015) - using their data set of intrauterine BMI-for-age growth curves. For

179 infants discharged later than 42 weeks of GA, BMI percentiles could not be calculated and

180 data is therefore missing. The difference of Z-scores from birth to discharge is reported in

181 Table 6. Growth failure was categorized according to Shah et al (Shah et al. 2006) as having

182 no $(\Delta \mathrm{Z}$-score higher than -1 SD), mild ( $\Delta$ Z-score between -1 to - $2 \mathrm{SD})$ or severe ( $\Delta$ Z-score

183 below -2 SD) growth failure and is expressed as the percentage of discharged infants

184 (Figure 1).

185 Statistics 
186 Statistical analysis was performed using the $\chi^{2}$-test for categorical data; student's t and

187 Mann Whitney U-test were used for continuous data depending on their normal

188 distribution as appropriate. For statistical analysis of BMI percentiles from birth to

189 discharge, the paired student's t test was used. The primary outcome PNAC was analyzed

190 in a model of binary logistic regression to investigate the influence of "aggressive" nutrition

191 on PNAC corrected for relevant confounding factors of cholestasis (NEC and/or

192 gastrointestinal (GI) surgery, culture proven sepsis, birth weight, Z-score of birth weight,

193 time on PN and male sex) and the adjusted odds ratio is reported (Table 5). $P$-values $<0.05$

194 were regarded as statistically significant. Data represent the median and interquartile

195 range if not otherwise indicated.

\section{Ethics and registration}

197 Due to the retrospective nature of the study, parental informed consent was not considered necessary by the institute's ethics board that approved the study design (EK 2010/061).

199 The study was concomitantly registered at ClinicalTrials.gov as a retrospective cohort 200 study (NCT01164878).

\section{Acknowledgments}

202 The authors would like to thank Louise Lawson from the Department of Statistics and

203 Analytical Sciences at the Kennesaw State University (Georgia, U.S.A.) for calculating the

204 individual BMI Z-scores and percentiles and Irene Olsen from the University of

205 Pennsylvania (PA, U.S.A) for her permission to use the data. 


\section{RESULTS}

207 Screening

208 A total of 296 ELBW infants were born within the study period ("conservative" 01/2005 -

209 01/2006 (n=153), “aggressive" 07/2007- 06/2009 (n=143)). Of 296 infants screened, 162

210 infants ("conservative": n= 77, “aggressive": n= 85) were eligible. Reasons for exclusion

211 were death < 28 days of life ("conservative": $n=54$; "aggressive": $n=45$ ), transfer < 28 days

212 of life ("conservative": $n=21$; "aggressive": $n=13$ ) and congenital cytomegalovirus infection

213 ("conservative": $\mathrm{n=1}$ ).

\section{Demographic and basic clinical parameters}

215

216

\section{7}

218

219

220

221

222

223

224

225

Demographic and basic clinical parameters were not significantly different except for "male sex" (significantly higher proportion in the "conservative" group, Table 2).

\section{Nutritional analysis first week of life}

ELBW infants nourished using the "aggressive" regimen received significantly higher amounts of parenteral amino acids and lipids, but significantly less glucose compared to the "conservative" regimen (Table 3). The amount of parenteral fluids was equal, whereas enteral feeding volumes were almost twice as high using "aggressive" nutrition. Enteral nutrition provided four times more calories in the "aggressive" period and consecutively total energy was significantly higher. Time on PN was 5 days shorter using "aggressive" nutrition (statistically not significant).

\section{Neonatal outcome - morbidities}


226 The incidence of the primary outcome PNAC was significantly lower in the period of

227 “aggressive" (27.0\%) compared to “conservative" (45.5\%) nutrition (Table 4).

228 Furthermore, culture proven sepsis occurred significantly less often in the "aggressive"

229 period. Other parameters were not significantly different. In a multivariate analysis on the

230 effect of "aggressive" nutrition corrected for confounding variables of cholestasis the effect

231 of "aggressive" nutrition on the reduction of PNAC was statistically significant (adjusted OR

$2320.275, P<0.01$; Table 5).

\section{Neonatal outcome -growth}

234 Extreme low birth weight infants on "aggressive" nutrition were discharged at similar GA

235 but with significantly higher body weight $(+400 \mathrm{~g})$, length $(+1 \mathrm{~cm})$ and head circumference

$236(+1 \mathrm{~cm})$. Postnatal growth faltering was significantly decreased (Table 6) and the

237 percentage of infants diagnosed with "mild" or "severe" growth restriction was markedly

238 reduced (Figure 1). The positive effect on postnatal growth restriction was most

239 pronounced for body weight, followed by head circumference, and body length (Table 6,

240 Figure 1). At discharge, the median BMI in the "conservative" group was significantly lower

241 compared to the "aggressive" group, while there was no difference between the two groups

242 at birth (Table 2). The median BMI percentile at birth was similar in the "conservative" and

243 "aggressive" group. Infants of the "conservative" group showed a significant loss of BMI

244 percentiles from birth to discharge (from $29^{\text {th }}$ to $11^{\text {th }}$ percentile, $P=0.004$ ), while infants of

245 the "aggressive" group significantly gained BMI percentiles (from $23^{\text {rd }}$ to $41^{\text {st }}$ percentile,

$246 \mathrm{P}=0.004$; Tables 2 and 6). The proportion of infants discharged below the $10^{\text {th }} \mathrm{BMI}$

247 percentile was significantly lower after switching to "aggressive" nutrition, while the

248 percentage of infants discharged over the $90^{\text {th }}$ BMI percentile did not increase (Table 6). 
249 Characterization of infants with PNAC

250 ELBW infants without PNAC (Table 7) received higher amounts of enteral energy and fluids

251 and were weaned from PN significantly faster. Infants with PNAC of both periods were

252 born with a significantly lower birth weight and also Z-score of birth weight, displayed a

253 higher mortality and morbidity (NEC, BPD, PDA requiring medial treatment, ROP) and

254 were significantly longer hospitalized compared to infants without PNAC. 


\section{DISCUSSION}

256 Implementation of "aggressive" nutrition for ELBW infants was associated with a reduced

257 incidence of PNAC and improved weight, head circumference, length and BMI at discharge.

258 After implementing new nutrition guidelines at our unit, nutrition of ELBW infants was

259 performed more "aggressively". This included to introduce parenteral amino acids and

260 lipids earlier and at higher amounts, as well as to start enteral nutrition immediately after

261 birth with feeding advancements up to $20 \mathrm{ml} / \mathrm{kg} /$ day. To evaluate whether the new

262 guidelines were put into practice, we analyzed the nutritional intake in the first week of

263 life. Here, we found that ELBW infants received significantly more parenteral amino acids

264 and lipids, but less glucose (Table 3). The lower glucose supply was unexpected as glucose

265 was also started at increased amounts using the "aggressive" regimen (Table 1). It thus

266 seems that parenteral glucose needs were lowered, most probably because EFs were

267 started earlier and increased faster. Despite accelerating early feeding advancements, the

268 total time on PN was not significantly shortened ( -5 days, $\mathrm{P}=0.246$, Table 3$)$. We can only

269 speculate whether caution to avoid NEC or feeding intolerance slowed down care keepers

270 in weaning infants from PN. Maybe feeding advancements were simply not defined

271 rigorously enough, but the data on safety in ELBW infants are still to limited (Morgan et al.

272 2015) to justify a fixed feeding advancement. Finally, it may as well represent a power

273 problem and a significant difference might have been detectable if a larger group of infants

274 had been recruited.

275 We were concerned about a negative impact of "aggressive" nutrition on PNAC - due to the

276 early increase of amino acids (Steinbach et al. 2008) and lipids (Carter et al. 2007; Clayton 
277 et al. 1993; Kurvinen et al. 2012) in PN - especially since one randomized trial of

278 "aggressive" PN showed a significant increase of total bilirubin in very low birth weight

279 (VLBW, $<1500 \mathrm{~g}$ birth weight) infants using "aggressive" PN (Ibrahim et al. 2004). Also the

280 influence of initiating EFs with full strength preterm formula instead of diluted hydrolyzed

281 feedings and earlier fortification on the incidence of PNAC, feeding tolerance and NEC

282 (Pearson et al. 2013) are ill-defined. It was therefore re-assuring to find that the incidence

283 of PNAC was even significantly reduced (Tables 4 and 5) after modifying our feeding

284 regimen. The severity of PNAC did not change as mortality and the highest conjugated

285 bilirubin levels were relatively similar ("conservative" 5.0 vs. "aggressive" $4.7 \mathrm{mg} / \mathrm{dl}$, Table

286 4). The severity of PNAC in our study infants was generally comparable to another study in

287 VLBW infants by Costa et al. using a rather "conservative" nutritional regimen (4.9 - 5.2

$288 \mathrm{mg} / \mathrm{dl}$ direct bilirubin (Costa et al. 2010)). Concerning the tolerance of more aggressive

289 enteral nutrition, we observed a stable NEC rate between groups and speculate that the

290 faster progression of EFs with higher osmolality had no negative impact. Sepsis is an

291 important trigger for cholestasis and culture proven sepsis was significantly lower in the

292 period of "aggressive" nutrition. Interestingly, the patient-related risk factors for sepsis

293 (time on PN, BPD, NEC and birth weight ((Stoll et al. 2002)) did not significantly differ

294 between the two periods. A relation of "aggressive" nutrition to reduction of sepsis can

295 therefore not be excluded, but the effect is more likely caused by hygiene improvements

296 (Legeay et al. 2015) at our unit.

297 To exclude that other factors besides a more "aggressive" nutritional regimen - especially

298 the lower sepsis rate - reduced PNAC, we performed a multivariate analysis (Table 5)

299 including sepsis (Beale et al. 1979; Beath et al. 1996; Drongowski \& Coran 1989), low birth 
300 weight (Beale et al. 1979), NEC/GI surgery (Moss et al. 1996; Veenstra et al. 2014),

301 duration of PN (Zambrano et al. 2004), male sex (Albers et al. 2002; Bines 2004) and Z-

302 score of birth weight. While most factors are well established, the data on the significance

303 of intrauterine growth restriction are controversial (Costa et al. 2010; Robinson \&

304 Ehrenkranz 2008). As infants with PNAC showed significantly lower Z-scores of birth

305 weight in our study (Table 7), the degree of growth retardation seemed relevant in our

306 cohort and was therefore included into analysis. We did not correct for duration of

307 hospitalization and neonatal morbidities like BPD, ROP or PDA - that had a significantly

308 higher prevalence in infants with PNAC (Table 7) - as these factors are no risk factors for

309 PNAC, but rather linked to PNAC via low birth weight. We further did not include

310 fluconazole prophylaxis, as its association with PNAC (Aghai et al. 2006) was not confirmed

311 by randomized trials (Ericson et al. 2016). After considering all confounders the effect of

312 "aggressive" nutrition on the reduction of PNAC still remained statistically significant

313 (adjusted OR 0.275, Table 5). Due to the retrospective nature of the study, it is still possible

314 that there may be other confounding factors not considered within the study.

315 As PNAC remained significantly reduced after correction for non-nutritional confounders it seems most plausible, that nutritional factors - modified by "aggressive" nutrition - were

317 involved. In view of the lack of literature on "aggressive" or "conservative" nutrition of

318 ELBW infants and PNAC incidence, the putative mechanisms deserve some more attention.

319 "Aggressive" nutrition contained a bundle of changes to our feeding regimen (Table 1) that 320 are related to PNAC. One explanation how PNAC is reduced by "aggressive" nutrition could 321 be a reduction of the time on PN (Zambrano et al. 2004) and thus a reduced exposure to 322 soybean oil based lipids (Carter et al. 2007; Clayton et al. 1993; Kurvinen et al. 2012). 
323 Furthermore enteral nutrition right after birth (Drongowski \& Coran 1989; Yip et al. 1990)

324 is enhanced, thus stimulating bile flow. In our cohort, infants with PNAC generally received

325 PN significantly longer (Table 7), which also implicates a higher cumulative amount of

326 parenteral lipids (Nayrouz \& Amin 2014). As significantly more parenteral lipids were

327 applied in the first week of life using "aggressive" nutrition (Table 3), it seems questionable

328 whether a reduced lipid exposure could be part of the observed reduction of PNAC after

329 changing our nutritional regimen. Nevertheless, there was also a trend towards a reduced

330 time on PN and infants still may have received a lower cumulative amount of soybean oil

331 based lipids. It is however a limitation of our study, that our nutritional analysis did not

332 extend beyond the first week of life and we cannot answer this question in our setting. On

333 the other hand, early enteral nutrition was significantly enhanced after establishing

334 "aggressive" nutrition, with almost twice as much EFs applied in the first week of life (Table

3353 3) and early enteral nutrition had a positive influence against PNAC (Table 7). It thus

336 seems, that early stimulation of bile flow by "aggressive" enteral nutrition was a relevant

337 factor for prevention of PNAC - while we cannot exclude a role of a reduced cumulative

338 amount of lipids.

339 Postnatal growth restriction was common at our unit as elsewhere (Ehrenkranz et al.

340 1999). By implementing "aggressive" nutrition, we could markedly improve weight gain,

341 head and also linear growth of ELBW infants (Table 6). In particular, severe postnatal

342 growth faltering of weight $(<-2 \mathrm{SD})$ - which is associated with unfavorable

343 neurodevelopment (Shah et al. 2006) - could almost be completely avoided (Figure 1). The

344 aim of nutritional care of preterm infants is defined as reaching a postnatal growth that is

345 comparable to the healthy human fetus (AAP 1985). In this respect, the proportion of 
346 ELBW infants without faltering of weight gain increased from $15 \%$ to $65 \%$ while the

347 median Z-score loss of body weight improved from -1.7 to -0.82. Interestingly, a Z-score

348 loss of -0.8 corresponds to what was recently defined as natural weight loss by

349 extracellular contraction in a multicenter cohort of healthy VLBW infants (Rochow et al.

350 2016), which is therefore encouraging. However, the improvements in normal head growth

351 (from 28\% to 55\%) and linear growth (from 15\% to 35\%) at our unit were less

352 pronounced. The finding that weight and head circumference are more susceptible to

353 nutritional intervention than linear growth are quite similar to Roggero et al, who reported

354 improved weight and head circumference, but not length after introducing a comparable

355 nutritional regimen (Roggero et al. 2012). Such “disproportionate" postnatal growth

356 characterized by primarily stunting (Ramel et al. 2012) raises concerns about body

357 composition and potential adverse metabolic effects (Yeung 2006). In this context, we

358 found that the BMI at discharge was significantly higher using "aggressive" compared to

359 "conservative" nutrition (Table 6). Recently, Olsen et al published fetal BMI percentiles that

360 enable to evaluate the relation of lean and fat mass of hospitalized preterm infants (Olsen

361 et al. 2015). Roughly a quarter of ELBW infants in our study were born with a BMI below

362 the $10^{\text {th }}$ percentile (Table 2). Calculating the BMI percentiles we found that infants of the

363 "conservative" period lost a BMI trajectory from birth (29) percentile) to discharge $\left(11^{\text {th }}\right.$

364 percentile) and that the proportion of infants discharged below the $10^{\text {th }}$ BMI percentile

365 doubled to almost 50 percent (Tables 2 and 6). On the contrary, infants of the "aggressive"

366 group gained one trajectory from the $24^{\text {th }}$ to the $41^{\text {st }} \mathrm{BMI}$ percentile and the proportion

367 discharged below the $10^{\text {th }}$ BMI percentile dropped below 10 percent. Concerning a possible

368 adverse health effect due to overfeeding, there was no increase in the proportion of infants 
369 that were discharged with a BMI over the $90^{\text {th }}$ BMI percentile (Table 6). Thus, growth 370 generally became more proportionate using the "aggressive" regimen and - given the

371 correlation of BMI with fat mass in preterm infants (Cooke \& Griffin 2009) - these findings

372 suggest that exaggerated fat accumulation did not happen. Unfortunately we cannot

373 present any data on direct measurement of body composition due to the retrospective

374 nature of the study. Future prospective studies that aim at further improving especially

375 linear growth of preterm infants should probably not be performed without direct

376 measurement of body composition (Rice \& Valentine 2015) to evaluate potentially

377 unhealthy growth.

CONCLUSION

Our study showed that a combined approach of "aggressive" parenteral and enteral nutrition significantly reduced PNAC while improving postnatal growth in a proportionate manner.

\section{ACKNOWLEDGMENTS}

The authors would like to thank Louise Lawson from the Department of Statistics and Analytical Sciences at the Kennesaw State University (Georgia, U.S.A.) for calculating the

387 individual BMI percentiles and Z-scores and Irene Olsen from the University of

388 Pennsylvania (Pennsylvania, U.S.A) for her permission to use the data. 
390

391

392

393

394

395

396

397

398

399

400

401

402

403

404

405

406

407

408

409

410

411

412

\section{REFERENCES}

AAP. 1985. American Academy of Pediatrics Committee on Nutrition: Nutritional needs of lowbirth-weight infants. Pediatrics 75:976-986.

Aghai ZH, Mudduluru M, Nakhla TA, Amendolia B, Longo D, Kemble N, Kaki S, Sutsko R, Saslow JG, and Stahl GE. 2006. Fluconazole prophylaxis in extremely low birth weight infants: association with cholestasis. Journal of perinatology : official journal of the California Perinatal Association 26:550-555. 10.1038/sj.jp.7211570

Albers MJ, de Gast-Bakker DA, van Dam NA, Madern GC, and Tibboel D. 2002. Male sex predisposes the newborn surgical patient to parenteral nutrition-associated cholestasis and to sepsis. Archives of surgery 137:789-793.

Aly H, Abdel-Hady H, Khashaba M, and El-Badry N. 2007. Erythromycin and feeding intolerance in premature infants: a randomized trial. Journal of perinatology : official journal of the California Perinatal Association 27:39-43. 10.1038/sj.jp.7211618

Beale EF, Nelson RM, Bucciarelli RL, Donnelly WH, and Eitzman DV. 1979. Intrahepatic cholestasis associated with parenteral nutrition in premature infants. Pediatrics 64:342-347.

Beath SV, Davies P, Papadopoulou A, Khan AR, Buick RG, Corkery JJ, Gornall P, and Booth IW. 1996. Parenteral nutrition-related cholestasis in postsurgical neonates: multivariate analysis of risk factors. Journal of pediatric surgery 31:604-606.

Bines JE. 2004. Parenteral Nutrition Associated Liver Disease. In: Walker WA, ed. Walker's pediatric gastrointestinal disease: physiology, diagnosis, managment. 4th ed, 1455-1456.

Carter BA, Taylor OA, Prendergast DR, Zimmerman TL, Von Furstenberg R, Moore DD, and Karpen SJ. 2007. Stigmasterol, a soy lipid-derived phytosterol, is an antagonist of the bile acid nuclear receptor FXR. Pediatr Res 62:301-306. 10.1203/PDR.0b013e3181256492 
413 Clayton PT, Bowron A, Mills KA, Massoud A, Casteels M, and Milla PJ. 1993. Phytosterolemia in

414

415

416

417

418

419

420

421

422

423

424

425

426

427

428

429

430

431

432

433

434

435

436

437

children with parenteral nutrition-associated cholestatic liver disease. Gastroenterology 105:1806-1813.

Cooke RJ, and Griffin I. 2009. Altered body composition in preterm infants at hospital discharge. Acta paediatrica 98:1269-1273. 10.1111/j.1651-2227.2009.01354.x

Costa S, Maggio L, Sindico P, Cota F, De Carolis MP, and Romagnoli C. 2010. Preterm small for gestational age infants are not at higher risk for parenteral nutrition-associated cholestasis. The Journal of pediatrics 156:575-579. 10.1016/j.jpeds.2009.10.038

de Vries LS, Eken P, and Dubowitz LM. 1992. The spectrum of leukomalacia using cranial ultrasound. Behav Brain Res 31:1-6.

Doumas BT, and Wu TW. 1991. The measurement of bilirubin fractions in serum. Crit Rev Clin Lab Sci 28:415-445. 10.3109/10408369109106872

Drongowski RA, and Coran AG. 1989. An analysis of factors contributing to the development of total parenteral nutrition-induced cholestasis. JPEN Journal of parenteral and enteral nutrition 13:586-589.

Ehrenkranz RA, Younes N, Lemons JA, Fanaroff AA, Donovan EF, Wright LL, Katsikiotis V, Tyson JE, Oh W, Shankaran S, Bauer CR, Korones SB, Stoll BJ, Stevenson DK, and Papile LA. 1999. Longitudinal growth of hospitalized very low birth weight infants. Pediatrics 104:280-289.

Embleton NE, Pang N, and Cooke RJ. 2001. Postnatal malnutrition and growth retardation: an inevitable consequence of current recommendations in preterm infants? Pediatrics 107:270-273.

Ericson JE, Kaufman DA, Kicklighter SD, Bhatia J, Testoni D, Gao J, Smith PB, Prather KO, Benjamin DK, Jr., Fluconazole Prophylaxis Study Team on behalf of the Best Pharmaceuticals for Children Act-Pediatric Trials Network Steering C, and Fluconazole Prophylaxis Study Team on behalf of the Best Pharmaceuticals for Children Act-Pediatric Trials Network Steering C. 
2016. Fluconazole Prophylaxis for the Prevention of Candidiasis in Premature Infants: A Meta-analysis Using Patient-level Data. Clin Infect Dis. 10.1093/cid/ciw363

440

441

442

443

444

445

446

447

448

449

450

451

452

453

454

455

456

457

458

459

460

Fanaroff AA, Stoll BJ, Wright LL, Carlo WA, Ehrenkranz RA, Stark AR, Bauer CR, Donovan EF, Korones SB, Laptook AR, Lemons JA, Oh W, Papile LA, Shankaran S, Stevenson DK, Tyson JE, Poole WK, and Network NNR. 2007. Trends in neonatal morbidity and mortality for very low birthweight infants. Am J Obstet Gynecol 196:147 e141-148. 10.1016/j.ajog.2006.09.014

Fenton TR. 2013. Research Bulk Calculator Available at http://ucalgary.ca/fenton/2013chart (accessed 6 March 2015).

Fenton TR, and Kim JH. 2013. A systematic review and meta-analysis to revise the Fenton growth chart for preterm infants. BMC Pediatr 13:59. 10.1186/1471-2431-13-59

Gokmen T, Oguz SS, Bozdag S, Erdeve O, Uras N, and Dilmen U. 2012. A controlled trial of erythromycin and UDCA in premature infants during parenteral nutrition in minimizing feeding intolerance and liver function abnormalities. Journal of perinatology : official journal of the California Perinatal Association 32:123-128. 10.1038/jp.2011.56

Guellec I, Gascoin G, Beuchee A, Boubred F, Tourneux P, Ramful D, Zana-Taieb E, and Baud 0. 2015. Biological Impact of Recent Guidelines on Parenteral Nutrition in Preterm Infants: A Systematic Review. Journal of pediatric gastroenterology and nutrition. 10.1097/MPG.0000000000000898

Hay WW, Jr. 2013. Aggressive Nutrition of the Preterm Infant. Curr Pediatr Rep 1. 10.1007/s40124013-0026-4

Horn W, Popow C, Miksch S, Kirchner L, and Seyfang A. 2002. Development and evaluation of VIEPNN, a knowledge-based system for calculating the parenteral nutrition of newborn infants. Artif Intell Med 24:217-228. 
461 Ibrahim HM, Jeroudi MA, Baier RJ, Dhanireddy R, and Krouskop RW. 2004. Aggressive early total

462

463

464

465

466

467

468

469

470

471

472

473

474

475

476

477

478

479

480

481

482

483

484

485

parental nutrition in low-birth-weight infants. Journal of perinatology : official journal of the California Perinatal Association 24:482-486. 10.1038/sj.jp.7211114

Kelly DA. 1998. Liver complications of pediatric parenteral nutrition--epidemiology. Nutrition 14:153-157.

Klebermass-Schrehof K, Wald M, Schwindt J, Grill A, Prusa AR, Haiden N, Hayde M, Waldhoer T, Fuiko R, and Berger A. 2013. Less invasive surfactant administration in extremely preterm infants: impact on mortality and morbidity. Neonatology 103:252-258. 10.1159/000346521

Klein CJ, Revenis M, Kusenda C, and Scavo L. 2010. Parenteral nutrition-associated conjugated hyperbilirubinemia in hospitalized infants. J Am Diet Assoc 110:1684-1695.

Kurvinen A, Nissinen MJ, Andersson S, Korhonen P, Ruuska T, Taimisto M, Kalliomaki M, Lehtonen L, Sankilampi U, Arikoski P, Saarela T, Miettinen TA, Gylling H, and Pakarinen MP. 2012. Parenteral plant sterols and intestinal failure-associated liver disease in neonates. Journal of pediatric gastroenterology and nutrition 54:803-811. 10.1097/MPG.0b013e3182474118

Legeay C, Bourigault C, Lepelletier D, and Zahar JR. 2015. Prevention of healthcare-associated infections in neonates: room for improvement. $J$ Hosp Infect 89:319-323. 10.1016/j.jhin.2015.02.003

Morgan J, Young L, and McGuire W. 2011. Slow advancement of enteral feed volumes to prevent necrotising enterocolitis in very low birth weight infants. Cochrane Database Syst Rev:CD001241. 10.1002/14651858.CD001241.pub3

Morgan J, Young L, and McGuire W. 2015. Slow advancement of enteral feed volumes to prevent necrotising enterocolitis in very low birth weight infants. Cochrane Database Syst Rev 10:CD001241. 10.1002/14651858.CD001241.pub6

Moss RL, Das JB, and Raffensperger JG. 1996. Necrotizing enterocolitis and total parenteral nutrition-associated cholestasis. Nutrition 12:340-343. 
486 Nayrouz MM, and Amin SB. 2014. Cumulative amount of intravenous lipid intake and parenteral

487

488

489

490

491

492

493

494

495

496

497

498

499

500

501

502

503

504

505

506

507

508

509 nutrition-associated cholestasis in neonates with gastrointestinal surgical disorders. $\mathrm{Am} J$ Perinatol 31:419-424. 10.1055/s-0033-1352481

Ng PC, Lee CH, Wong SP, Lam HS, Liu FY, So KW, Lee CY, and Fok TF. 2007. High-dose oral erythromycin decreased the incidence of parenteral nutrition-associated cholestasis in preterm infants. Gastroenterology 132:1726-1739. 10.1053/j.gastro.2007.03.043

Olsen IE, Lawson ML, Ferguson AN, Cantrell R, Grabich SC, Zemel BS, and Clark RH. 2015. BMI curves for preterm infants. Pediatrics 135:e572-581. 10.1542/peds.2014-2777

Pearson F, Johnson MJ, and Leaf AA. 2013. Milk osmolality: does it matter? Archives of disease in childhood Fetal and neonatal edition 98:F166-169. 10.1136/adc.2011.300492

Pereira GR. 1995. Nutritional care of the extremely premature infant. Clinics in perinatology 22:6175.

Ramel SE, Demerath EW, Gray HL, Younge N, Boys C, and Georgieff MK. 2012. The relationship of poor linear growth velocity with neonatal illness and two-year neurodevelopment in preterm infants. Neonatology 102:19-24. 10.1159/000336127

Rice MS, and Valentine CJ. 2015. Neonatal Body Composition: Measuring Lean Mass as a Tool to Guide Nutrition Management in the Neonate. Nutrition in clinical practice : official publication of the American Society for Parenteral and Enteral Nutrition 30:625-632. $10.1177 / 0884533615578917$

Robinson DT, and Ehrenkranz RA. 2008. Parenteral nutrition-associated cholestasis in small for gestational age infants. The Journal of pediatrics 152:59-62. 10.1016/j.jpeds.2007.06.002

Rochow N, Raja P, Liu K, Fenton T, Landau-Crangle E, Gottler S, Jahn A, Lee S, Seigel S, Campbell D, Heckmann M, Poschl J, and Fusch C. 2016. Physiological adjustment to postnatal growth trajectories in healthy preterm infants. Pediatr Res. 10.1038/pr.2016.15 
510 Roggero P, Gianni ML, Orsi A, Amato O, Piemontese P, Liotto N, Morlacchi L, Taroni F, Garavaglia E,

511 Bracco B, Agosti M, and Mosca F. 2012. Implementation of nutritional strategies decreases

512 postnatal growth restriction in preterm infants. PloS one 7:e51166.

$513 \quad$ 10.1371/journal.pone.0051166

514 Shah PS, Wong KY, Merko S, Bishara R, Dunn M, Asztalos E, and Darling PB. 2006. Postnatal growth

515 failure in preterm infants: ascertainment and relation to long-term outcome. J Perinat Med $516 \quad 34: 484-489.10 .1515 / J P M .2006 .094$

517 Steinbach M, Clark RH, Kelleher AS, Flores C, White R, Chace DH, and Spitzer AR. 2008. 518 Demographic and nutritional factors associated with prolonged cholestatic jaundice in the premature infant. Journal of perinatology : official journal of the California Perinatal Association 28:129-135. 10.1038/sj.jp.7211889

521

522

523

524

525

526

527

528

529

530

531

532

533

534

Stoll BJ, Hansen N, Fanaroff AA, Wright LL, Carlo WA, Ehrenkranz RA, Lemons JA, Donovan EF, Stark AR, Tyson JE, Oh W, Bauer CR, Korones SB, Shankaran S, Laptook AR, Stevenson DK, Papile LA, and Poole WK. 2002. Late-onset sepsis in very low birth weight neonates: the experience of the NICHD Neonatal Research Network. Pediatrics 110:285-291.

Tsang RC, Uauy, Koletzko B, and Zlotkin. 2005. Nutrition of the preterm infant- scientific basis and practical guidelines: Digital Educational Publishing, INC.

Veenstra M, Danielson L, Brownie E, Saba M, Natarajan G, and Klein M. 2014. Enteral nutrition and total parenteral nutrition components in the course of total parenteral nutrition-associated cholestasis in neonatal necrotizing enterocolitis. Surgery 156:578-583. 10.1016/j.surg.2014.04.031

Volpe JJ. 1989. Intraventricular hemorrhage and brain injury in the premature infant. Diagnosis, prognosis, and prevention. Clinics in perinatology 16:387-411.

Walsh MC, and Kliegman RM. 1986. Necrotizing enterocolitis: treatment based on staging criteria. Pediatr Clin North Am 33:179-201. 
535 Ye W, Rosenthal P, Magee JC, Whitington PF, Childhood Liver Disease R, and Education N. 2015.

536 Factors Determining delta-Bilirubin Levels in Infants With Biliary Atresia. Journal of 537 pediatric gastroenterology and nutrition 60:659-663. 10.1097/MPG.0000000000000690

538 Yeung MY. 2006. Postnatal growth, neurodevelopment and altered adiposity after preterm birth-539 from a clinical nutrition perspective. Acta paediatrica 95:909-917. $540 \quad 10.1080 / 08035250600724507$

541 Yip YY, Lim AK, R J, and Tan KL. 1990. A multivariate analysis of factors predictive of parenteral 542 nutrition-related cholestasis (TPN cholestasis) in VLBW infants. J Singapore Paediatr Soc $543 \quad 32: 144-148$.

544 Zambrano E, El-Hennawy M, Ehrenkranz RA, Zelterman D, and Reyes-Mugica M. 2004. Total 545 parenteral nutrition induced liver pathology: an autopsy series of 24 newborn cases. Pediatr 546 Dev Pathol 7:425-432. 10.1007/s10024-001-0154-7 


\section{Fig. 1}

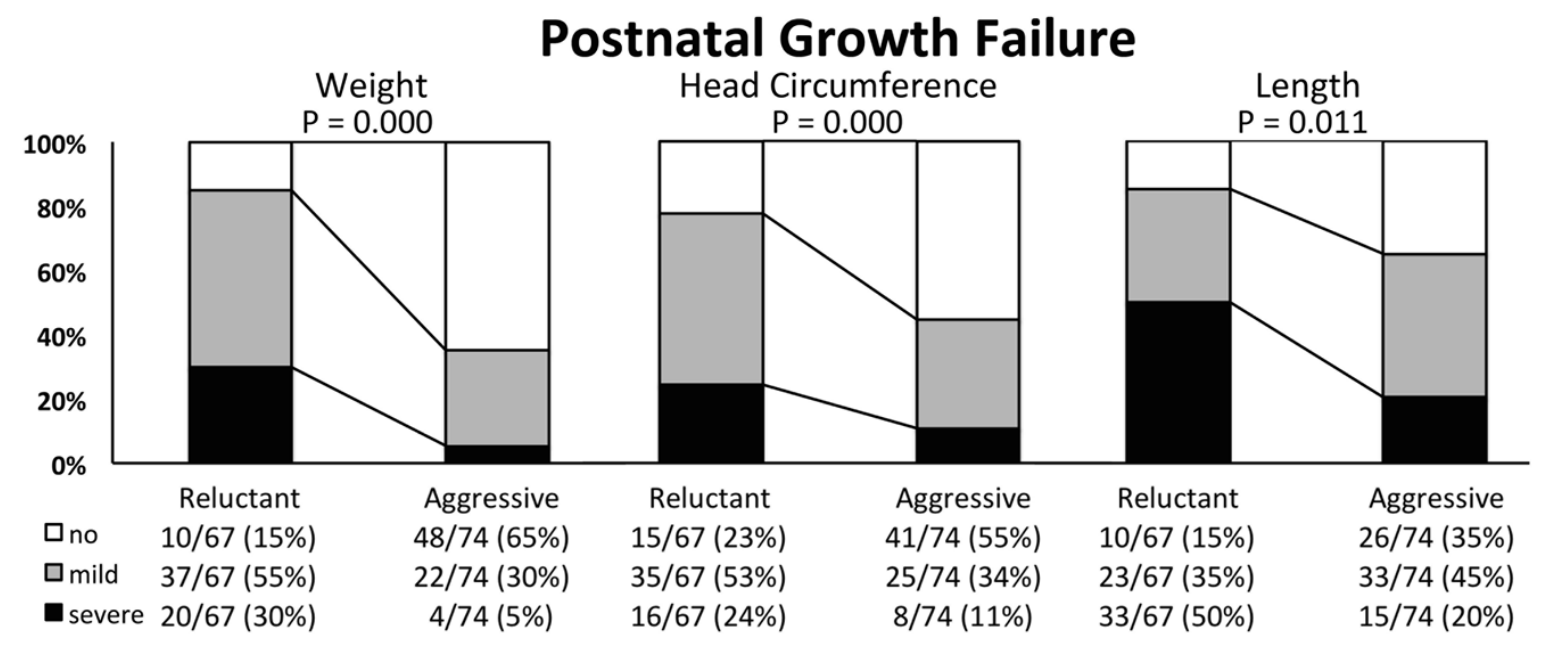

556 Postnatal growth failure of weight, head circumference and length in extremely low birth

557 weight infants nourished using a "conservative" or "aggressive" nutritional regimen.

558 Categorisation of postnatal growth failure was performed according to the difference in Z-

559 score ( $\Delta$ Z-score in standard deviations, SD) from birth to discharge as "no" (white bars;

$560 \Delta$ ? ? -score? ?higher than -1 SD), "mild" (grey bars, $\Delta$ Z-score ?between -1 and -2 SD) or

561 "severe" (black bars, $\Delta$ Z-score? ?below -2 SD). Data are presented as cases/total infants

562 with percentages in parentheses. The difference in the distribution of infants with growth

563 failure ("mild" and "severe") and those without ("no") was tested using the Chi Square test.

$564 P<0.05$ was considered statistically siginficant. 
Table 1. Guidelines on nutrition of ELBW infants

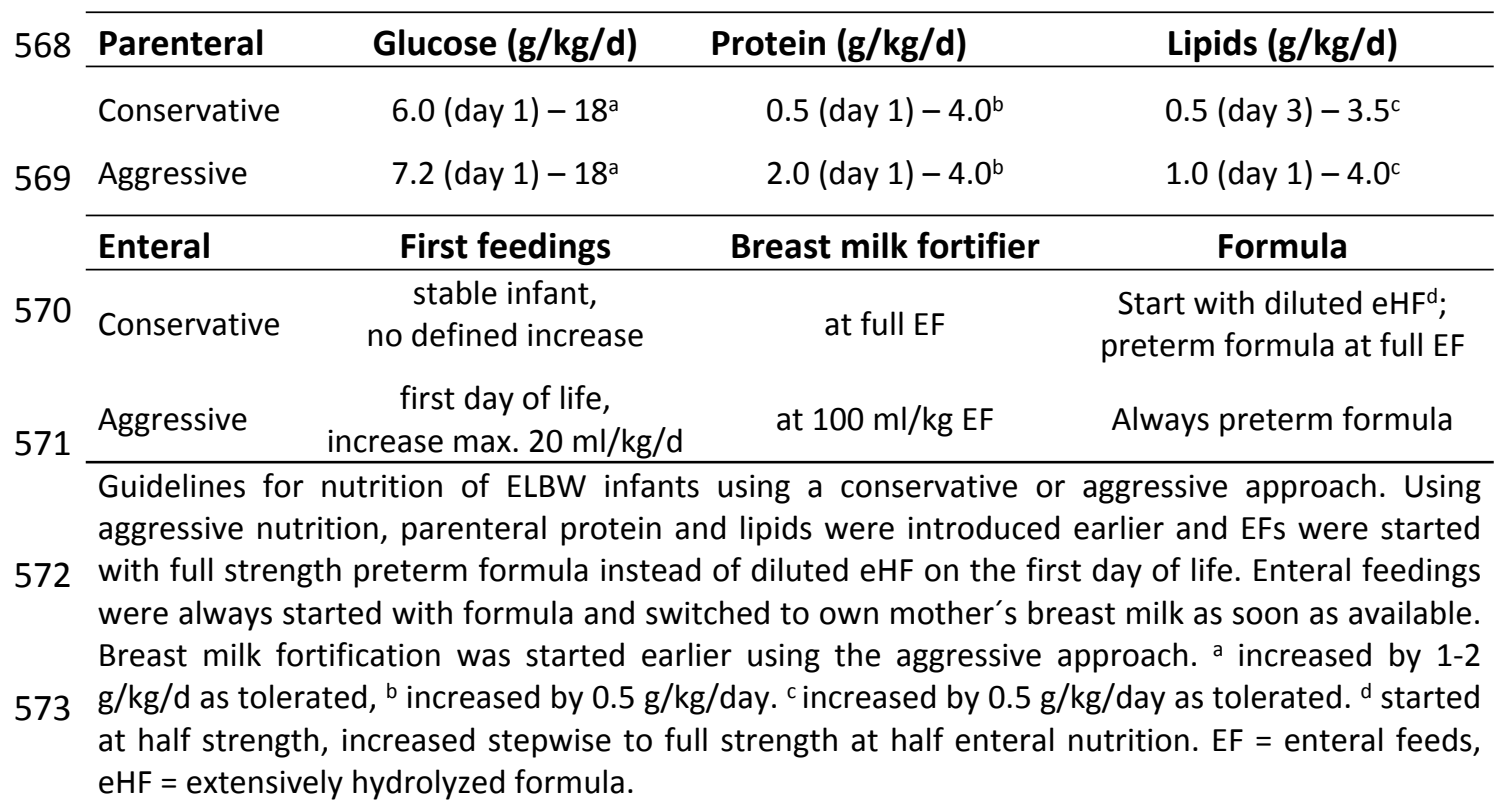

574

575 
578 Table 2. Demographic and basic clinical parameters

\begin{tabular}{|c|c|c|c|c|}
\hline & & $\begin{array}{c}\text { Conservative } \\
(n=77)\end{array}$ & $\begin{array}{l}\text { Aggressive } \\
(n=85)\end{array}$ & $\boldsymbol{P}$ \\
\hline \multirow[t]{2}{*}{579} & Male sex & $28(36)^{\mathrm{a}}$ & $47(55)^{a}$ & 0.018 \\
\hline & Multiples & $19(25)^{\mathrm{a}}$ & $28(33)^{\mathrm{a}}$ & 0.406 \\
\hline \multirow{3}{*}{580} & Cesarean section & $56(73)^{\mathrm{a}}$ & $63(74)^{a}$ & 0.860 \\
\hline & Prenatal steroids & $51(66)^{a}$ & $66(78)^{a}$ & 0.074 \\
\hline & PROM & $44(57)^{a}$ & $41(48)^{a}$ & 0.164 \\
\hline \multirow[t]{3}{*}{581} & Preeclampsia & $15(19)^{\mathrm{a}}$ & $8(9)^{a}$ & 0.054 \\
\hline & Apgar - 5 minutes & $8[8-9]^{b, c}$ & $9[8-9]^{b, d}$ & 0.339 \\
\hline & Surfactant & $58(75)^{\mathrm{a}}$ & $66(78)^{a}$ & 0.435 \\
\hline \multirow[t]{2}{*}{582} & Gestational age & $26+5[25+4-28+0]^{b}$ & $26+6[25+2-28+0]^{\mathrm{b}}$ & 0.795 \\
\hline & Birth weight (g) & $795[677-888]^{b}$ & $790[660-890]^{b}$ & 0.527 \\
\hline \multirow{3}{*}{583} & Percentile & $34[16-53]^{b}$ & $26[13 .-45 .]^{\mathrm{b}}$ & 0.331 \\
\hline & Z-score & $-0.4[-1--0.1]^{\mathrm{b}}$ & $-0.6[-1.2--0.1]^{\mathrm{b}}$ & 0.455 \\
\hline & Birth length $(\mathrm{cm})$ & $33.4[32.0-35.0]^{\mathrm{b}}$ & $33.0[31.0-35.0]^{\mathrm{b}}$ & 0.559 \\
\hline \multirow[t]{2}{*}{584} & Percentile & $29[8-49]^{\mathrm{b}}$ & $22[9-49]^{\mathrm{b}}$ & 0.717 \\
\hline & Z-score & $-0.6[-1.4-0.0]^{b}$ & $-0.8[-1.4--0.1]^{b}$ & 0.634 \\
\hline \multirow{3}{*}{585} & Birth head circumference $(\mathrm{cm})$ & $23.8[22.2-25.0]^{\mathrm{b}}$ & $23.5[22.3-24.5]^{b}$ & 0.634 \\
\hline & Percentile & $32[14-50]^{b}$ & $29[13-50]^{\mathrm{b}}$ & 0.611 \\
\hline & Z-score & $-0.5[-1.1-0.1]^{b}$ & $-0.6[-1.1-0.0]^{b}$ & 0.596 \\
\hline \multirow[t]{3}{*}{586} & Birth body mass index & $7.0(6.5-7.6)$ & $6.9(6.3-7.7)$ & 0.857 \\
\hline & Percentile & $29.1[9.0-58.3]$ & $23.9[4.9-52.3]$ & 0.505 \\
\hline & $<10^{\text {th }}$ & $20(26.0)^{\mathrm{a}}$ & $28(33.0)^{\mathrm{a}}$ & 0.390 \\
\hline \multirow[t]{2}{*}{587} & $>90^{\text {th }}$ & $3(3.9)^{\mathrm{a}}$ & $5(5.9)^{\mathrm{a}}$ & 0.722 \\
\hline & Z-score & $-0.6[-1.4 .-0.2]$ & $-0.7[-1.7-0.1]$ & 0.583 \\
\hline \multirow{2}{*}{588} & Small for Gestational Age & $17(22)^{a}$ & $17(20)^{a}$ & 0.454 \\
\hline & \multicolumn{4}{|c|}{ 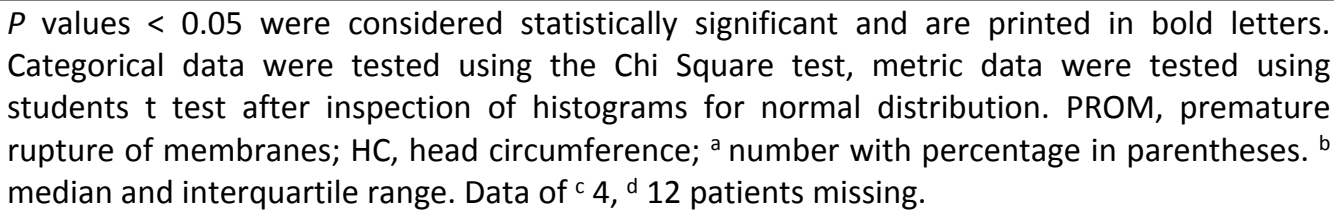 } \\
\hline
\end{tabular}

\section{Conservative}

590 
592 Table 3. Nutritional analysis

\begin{tabular}{|c|c|c|c|c|}
\hline \multirow[b]{2}{*}{593} & & $\begin{array}{c}\text { Conservative } \\
\qquad(n=77)\end{array}$ & $\begin{array}{l}\text { Aggressive } \\
(n=85)\end{array}$ & $\boldsymbol{P}$ \\
\hline & Total days on PN & $38[27-53.5]$ & $33[23-48]$ & 0.246 \\
\hline \multirow{3}{*}{594} & \multicolumn{4}{|l|}{ Parenteral ( $1^{\text {st }}$ week of life) } \\
\hline & Glucose $(\mathrm{g} / \mathrm{kg} / \mathrm{d})$ & $7.5[6.6-8.1]$ & $6.9[6.3-7.6]$ & 0.044 \\
\hline & Protein $(\mathrm{g} / \mathrm{kg} / \mathrm{d})$ & $1.9[1.45-2.5]$ & $2.8[2.6-3.0]$ & 0.000 \\
\hline \multirow{2}{*}{595} & Lipids (g/kg/d) & $1.2[1.1-1.5]$ & $1.9[1.6-2.3]$ & 0.000 \\
\hline & Fluids (ml/kg/d) & $126.9[114.5-139.6]$ & $124.6[108.8-144.5]$ & 0.891 \\
\hline \multirow{3}{*}{596} & Enteral ( $1^{\text {st }}$ week of life) & & & \\
\hline & Energy $(\mathrm{kcal} / \mathrm{kg} / \mathrm{d})$ & $5.1[2.9-9.6]$ & $19.7[13.0-32.1]$ & 0.000 \\
\hline & Fluids (ml/kg/d) & $13.4[8.2-21.7]$ & $24.8[16.5-40.3]$ & 0.000 \\
\hline \multirow[t]{3}{*}{597} & Total (1 $1^{\text {st }}$ week of life) & & & \\
\hline & Energy $(\mathrm{kcal} / \mathrm{kg} / \mathrm{d})$ & $50.8[44.2-55.7]$ & $70.4[60.3-77.8]$ & 0.000 \\
\hline & Fluids $(\mathrm{ml} / \mathrm{kg} / \mathrm{d})$ & $142.9[136.1-142.5]$ & $152.9[139.3-162.9]$ & 0.000 \\
\hline
\end{tabular}

598 Nutrition components, volumes and calories of ELBW infants in their first week of life were analyzed prior and after introduction of aggressive feedings. Data are presented as median and interquartile ranges. After inspection of histograms for normal distribution, total days 599 on PN were tested using the Mann Whitney $\mathrm{U}$ test, all other parameters using the student's $\mathrm{t}$ test. $P$ values $<0.05$ were considered statistically significant and printed in bold letters. $\mathrm{PN}=$ parenteral nutrition

600 
601

602 Table 4. Neonatal outcome - morbidity

\begin{tabular}{|c|c|c|c|c|c|c|}
\hline \multirow{3}{*}{603} & & $\begin{array}{c}\text { Conservative } \\
\qquad(n=77)\end{array}$ & missing & $\begin{array}{l}\text { Aggressive } \\
(\mathrm{n}=85)\end{array}$ & missing & $P$ \\
\hline & Hospitalization, days & $77[61-98]^{b}$ & & $78[58-100]^{b}$ & & 0.710 \\
\hline & Death & $9(11.7)^{a}$ & & $11(13.0)^{a}$ & & 1.000 \\
\hline \multirow{2}{*}{604} & PNAC & $35(45.5)^{a}$ & & $23(27.0)^{a}$ & & 0.021 \\
\hline & Onset (day of life) & $34[20-45]^{b}$ & & $30[12-39]^{b}$ & & 0.460 \\
\hline \multirow{3}{*}{605} & Peak conjugated bilirubin & $5.0[3.2-8.4]^{\mathrm{b}}$ & & $4.7[3.3-7.4]^{b}$ & & 0.851 \\
\hline & Mortality & $8 / 35(22.9)^{a}$ & & $5 / 23(21.7)^{a}$ & & 1.000 \\
\hline & Sepsis (culture proven) & $36(46.7)^{a}$ & & $25(29.4)^{a}$ & & 0.024 \\
\hline \multirow{3}{*}{606} & Necrotizing enterocolitis & $8(10.4)^{a}$ & & $8(9.4)^{a}$ & & 1.000 \\
\hline & Focal intestinal perforation & $1(1.3)^{\mathrm{a}}$ & & $1(1.2)^{\mathrm{a}}$ & & 0.726 \\
\hline & IVH grade $3 / 4$ & $14(18.1)^{a}$ & & $10(11.8)^{a}$ & & 0.275 \\
\hline \multirow[t]{2}{*}{607} & Surgery (any) & $26(33.8)^{a}$ & & $35(41.2)^{a}$ & & 0.209 \\
\hline & Surgery (GI) & $11(14.3)^{a}$ & & $8(9.4)^{a}$ & & 0.464 \\
\hline \multirow{3}{*}{608} & NEC and/or GI surgery & $12(15.6)^{a}$ & & $11(12.9)^{a}$ & & 0.658 \\
\hline & Cystic PVL & $3(3.9)^{a}$ & & $1(1.2)^{a}$ & & 0.274 \\
\hline & BPD & $19(24.6)^{\mathrm{a}}$ & $16(20.7)^{a}$ & $24(28.2)^{a}$ & $23(27.0)^{a}$ & 0.451 \\
\hline \multirow[t]{2}{*}{609} & Steroids for BPD & $16(20.8)^{a}$ & & $10(11.8)^{a}$ & & 0.137 \\
\hline & Medical treatment for PDA & $44(57.1)^{a}$ & & $59(69.4)^{a}$ & & 0.141 \\
\hline \multirow{2}{*}{610} & ROP (any stage) & $18(23.3)^{\mathrm{a}}$ & $8(10.4)^{a}$ & $27(31.8)^{\mathrm{a}}$ & $11(12.9)^{a}$ & 0.209 \\
\hline & $\begin{array}{l}\text { Univariate analysis of neona } \\
\text { Square test; metric data we } \\
\text { statistically significant and } \\
\text { median and interquartile } \\
\text { intraventricular hemorrhag } \\
\text { dysplasia; PDA = persiste } \\
\text { gastrointestinal; }\end{array}$ & $\begin{array}{l}\text { l outcome parar } \\
\text { tested using the } \\
\text { inted in bold let } \\
\text { nge; PNAC = pa } \\
\text { PVL = periven } \\
\text { ductus arterio }\end{array}$ & $\begin{array}{l}\text { heters. Categ } \\
\text { student's t t } \\
\text { ers. a numb } \\
\text { renteral nut } \\
\text { ricular leucc } \\
\text { sus; ROP = }\end{array}$ & $\begin{array}{l}\text { orical data were } \\
\text { est. P values }<0 \\
\text { er with percenta } \\
\text { rition associated } \\
\text { malacia; BPD = } \\
\text { retinopathy of }\end{array}$ & $\begin{array}{l}\text { tested using } \\
05 \text { were cor } \\
\text { ge in parent } \\
\text { cholestasis } \\
\text { bronchopul }\end{array}$ & $\begin{array}{l}\text { the Chi } \\
\text { sidered } \\
\text { heses, b } \\
\text { IVH = } \\
\text { monary } \\
\text {; GI = }\end{array}$ \\
\hline
\end{tabular}

Conservative 
613

614 Table 5. Multivariate analysis on aggressive nutrition and the risk for PNAC

\begin{tabular}{llccc}
615 & & adjusted OR & $\mathbf{C l}$ & $\boldsymbol{P}$ \\
\cline { 2 - 5 } & Aggressive Nutrition & 0.273 & $0.115-0.645$ & $\mathbf{0 . 0 0 3}$ \\
616 & Male Sex & 2.163 & $0.951-4.920$ & 0.066 \\
& Sepsis & 1.097 & $0.468-2.573$ & 0.832 \\
& NEC and/or Gl surgery & 1.214 & $0.468-2.573$ & 0.764 \\
617 & Birth Weight & 0.998 & $0.994-1.002$ & 0.325 \\
& Total days on PN & 1.054 & $1.028-1.081$ & $\mathbf{0 . 0 0 0}$ \\
& Z-score of birth weight & 0.415 & $0.232-0.734$ & $\mathbf{0 . 0 0 3}$ \\
\hline
\end{tabular}

618 Binary logistic regression analysis showing the corrected odds for aggressive nutrition and PNAC correcting for the co-variates male sex, sepsis, necrotizing enterocolitis (NEC) and/or gastrointestinal (GI)

619 surgery, birth weight, duration of parenteral nutrition (PN) and the degree of growth retardation at birth. OR = odds ratio, $\mathrm{Cl}=95 \%$ confidence interval. $P$ values $<0.05$ were considered statistically

620 significant and printed in bold letters. 
622

623

624

Table 6. Neonatal outcome - Growth characteristics at discharge

\begin{tabular}{|c|c|c|c|}
\hline & $\begin{array}{c}\text { Conservative } \\
(n=67)\end{array}$ & $\begin{array}{c}\text { Aggressive } \\
(n=74)\end{array}$ & $\boldsymbol{P}$ \\
\hline Postmenstrual age & $38+2[36+5-39+5]^{a}$ & $38+2[36+6-39+6]^{a}$ & 0.991 \\
\hline Weight (g) & $2050[1802-2235]^{a}$ & $2461[2020-2783]^{a}$ & 0.000 \\
\hline Z-score (SD) & $-2.34[-2.85--1.74]^{a}$ & $-1.38[-1.9--0.74]^{a}$ & 0.000 \\
\hline$\Delta$ Z-score (SD) & $-1.7[-2.16--1.27]^{a}$ & $-0.82[-1.16--0.32]^{a}$ & 0.000 \\
\hline Length $(\mathrm{cm})$ & $43[41-45]^{\mathrm{a}}$ & $44[42-46]^{\mathrm{a}}$ & 0.017 \\
\hline Z-score (SD) & $-2.8[-3.9--2.3]^{\mathrm{a}}$ & $-2.1[-2.85--1.4]^{\mathrm{a}}$ & 0.000 \\
\hline$\Delta \mathrm{Z}$-score (SD) & $-2.1[-2.85--1.60]^{a}$ & $-1.35[-1.92--0.58]^{\mathrm{a}}$ & 0.000 \\
\hline Head circumference $(\mathrm{cm})$ & $30.6[29.5-31.5]^{a}$ & $31.6[30.3-33.0]^{a}$ & 0.007 \\
\hline Z-score (SD) & $-2.1[-2.8--1.5]^{\mathrm{a}}$ & $-1.4[-1.82--0.8]^{\mathrm{a}}$ & 0.000 \\
\hline$\Delta$ Z-score (SD) & $-1.5[-2.03--1.08]^{a}$ & $-0.8[-1.63--0.15]^{a}$ & 0.001 \\
\hline Body mass index & $11.1(10.3-11.9)^{c}$ & $12.4(11.1-13.7)$ & 0.000 \\
\hline Percentile & $11.8(3.8-33.3)^{\mathrm{d}}$ & $41.2(21.4-67.9)^{\mathrm{e}}$ & 0.000 \\
\hline$<10^{\text {th }}$ & $25(43.8)^{b, d}$ & $6(9.2)^{b, e}$ & 0.000 \\
\hline$>90^{\text {th }}$ & $2(2.6)^{b, d}$ & $3(4.6)^{b, e}$ & 0.562 \\
\hline Z-Score (SD) & $-1.2(-1.8--0.5)^{\mathrm{e}}$ & $-0.2(-0.8-0.5)^{e}$ & 0.000 \\
\hline$\Delta \mathrm{Z}$-score $(\mathrm{SD})$ & $-0.4(-1.1-0.2)^{\mathrm{e}}$ & $0.7(-0.4-1.4)^{\mathrm{e}}$ & 0.000 \\
\hline
\end{tabular}

633 Data were tested using students $t$ test after inspection of histograms for normal distribution. $P$ values $<0.05$ were considered statistically significant and printed in bold letters. a median and interquartile range. ${ }^{b}$ number with percentage in parentheses. Data of ${ }^{\mathrm{c}} 2,{ }^{\mathrm{d}} 10$, e 9 infants missing. $\mathrm{GA}=$ gestational age. $\mathrm{SD}=$ standard deviation. 
Table 7. Characteristics of infants with PNAC

\begin{tabular}{|c|c|c|c|}
\hline & PNAC & No PNAC & $\mathbf{P}$ \\
\hline \multicolumn{4}{|c|}{ NUTRITIONAL ANALYSIS $1^{\text {st }}$ WEEK } \\
\hline \multicolumn{4}{|c|}{ CONSERVATIVE PERIOD } \\
\hline Parenteral & $(n=35)^{*}$ & $(n=42)^{* *}$ & \\
\hline Total days on PN & $52[39-63]$ & $29[22-38]$ & 0.000 \\
\hline Glucose (g/kg/d) & $5.1[4.5-5.5]$ & $5.4[4.6-6.0]$ & 0.201 \\
\hline Protein $(\mathrm{g} / \mathrm{kg} / \mathrm{d})$ & $1.8[1.5-2.5]$ & $1.9[1.4-2.5]$ & 0.883 \\
\hline Lipids (g/kg/d) & $1.1[1.2-1.4]$ & $1.2[1.1-1.6]$ & 0.725 \\
\hline Fluids (ml/kg/d) & $130[118-142]$ & $122[106-138]$ & 0.141 \\
\hline \multicolumn{4}{|l|}{ Enteral } \\
\hline Energy (kcal/kg/week) & $4.1[2.6-7.0]$ & $6.4[3.4-12.9]$ & 0.005 \\
\hline Fluids $(\mathrm{ml} / \mathrm{kg} / \mathrm{d})$ & $8.0[6.5-11.7]$ & $13.7[6.9-27.4]$ & 0.009 \\
\hline \multicolumn{4}{|l|}{ AGGRESSIVE PERIOD } \\
\hline Parenteral & $(n=23)^{* *}$ & $(n=62)^{*}$ & \\
\hline Total days on PN & $44[30-81]$ & $30[22-43]$ & 0.003 \\
\hline Glucose (g/kg/d) & $4.7[4.5-5.6]$ & $4.8[4.4-5.3]$ & 0.939 \\
\hline Protein $(\mathrm{g} / \mathrm{kg} / \mathrm{d})$ & $2.9[2.7-3.0]$ & $2.5[2.8-3.1]$ & 0.404 \\
\hline Lipids (g/kg/d) & $1.8[1.5-2.0]$ & $1.9[1.6-2.3]$ & 0.177 \\
\hline Fluids (ml/kg/d) & 137 [117 - 149] & $124[101-138]$ & 0.089 \\
\hline \multicolumn{4}{|l|}{ Enteral } \\
\hline Energy (kcal/kg/week) & $15.5[8.2-29.7]$ & $20.1[15.1-34.0]$ & 0.073 \\
\hline Fluids (ml/kg/d) & $19.7[10.3-37.1]$ & $25.7[19.0-42.7]$ & 0.059 \\
\hline \multicolumn{4}{|c|}{ Basic clinical parameters, morbidity and growth } \\
\hline BOTH PERIODS & $(n=58)$ & $(n=104)$ & \\
\hline Gestational age & $26+1[25+1-28+0]^{b}$ & $26+5[25+3-27+6]^{b}$ & 0.440 \\
\hline Male sex & $30(51.7)$ & $45(43.2)$ & 0.327 \\
\hline Birth weight, g & $709[627-823]^{b}$ & $824[702-892]^{b}$ & 0.000 \\
\hline Z-score & $-0.75[-1.4--0.2]^{\mathrm{b}}$ & $-0.47[-0.9-+0.1]^{b}$ & 0.029 \\
\hline Apgar - 5 minutes & $8[7-9]^{b}$ & $8[8-9]^{b}$ & 0.112 \\
\hline Hospitalization, days & $94[67-109]^{\mathrm{b}}$ & $71[57-88]^{b}$ & 0.002 \\
\hline Death & $13(22.4)^{\mathrm{a}}$ & $7(6.7)^{\mathrm{a}}$ & 0.006 \\
\hline Sepsis (culture proven) & $27(46.6)^{a}$ & $34(32.7)^{a}$ & 0.092 \\
\hline Necrotizing enterocolitis & $12(20.7)^{\mathrm{a}}$ & $4(3.8)^{\mathrm{a}}$ & 0.001 \\
\hline IVH grade $3 / 4$ & $12(20.7)^{\mathrm{a}}$ & $12(11.5)^{\mathrm{a}}$ & 0.165 \\
\hline BPD & $25(57.6)^{a, * * *}$ & $18(17.3)^{a, \#}$ & 0.000 \\
\hline Medical treatment for PDA & $46(79.31)^{\mathrm{a}}$ & $57(54.8)^{\mathrm{a}}$ & 0.002 \\
\hline ROP (any stage) & $21(36.2)^{\mathrm{a}, \# \#}$ & 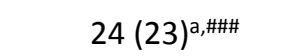 & 0.039 \\
\hline
\end{tabular}


634 Weight at discharge

Data were tested using the Chi Square test for categorical data and the student's $t$ test for continuous variables (except for total days on PN using Mann Whitney U Test). P values $<0.05$

635 were considered statistically significant and printed in bold letters. BPD = Bronchopulmonary Dysplasia; IVH = Intraventricular Hemorrhage; ROP = Retinopathy of Prematurity. ${ }^{\text {a }}$ number with percentage in parentheses, ${ }^{\mathrm{b}}$ median and interquartile range; Missing data: Data of ${ }^{*} 1,{ }^{*}$

$6363,{ }^{* * *} 13, \# 26, \# 9,{ }^{\# \#} 10$ infants missing.

637

638 